\title{
Computer and telephone delivered interventions to support caregivers of people with dementia: a systematic review of research output and quality
}

\author{
Amy Waller ${ }^{1,2,3^{*}}$ D, Sophie Dilworth ${ }^{1,2,3}$, Elise Mansfield ${ }^{1,2,3}$ and Rob Sanson-Fisher ${ }^{1,2,3}$
}

\begin{abstract}
Background: To assess the scope, volume and quality of research on the acceptability, utilisation and effectiveness of telephone- and computer-delivered interventions for caregivers of people living with dementia.

Methods: Medline, EMBASE, CINAHL and Cochrane databases were searched (Jan 1990 - Dec 2016). Eligible papers were classified as data-based descriptive, measurement or intervention studies. Intervention studies were first categorised according to mode of delivery (e.g. telephone, computer); then assessed against the Effective Practice and Organisation of Care (EPOC) methodological criteria for research design. Impact on health-related outcomes; and the acceptability,

feasibility and utilisation of interventions were also assessed.

Results: The number of publications increased by 13\% each year $(p<0.001)$. Half were descriptive studies $(n=92,50 \%)$ describing caregiver views on acceptability, access or utilization of technology. The remainder $(n=89,48 \%)$ reported on interventions designed to improve caregiver outcomes. Only 34 met EPOC design criteria. Interventions were delivered via computer $(n=10)$, multiple modalities $(n=9)$ or telephone $(n=15)$. Interventions that incorporated various elements of psycho-education, peer support, skills training and health assessments led to improvements in caregiver wellbeing. While largely acceptable, utilisation of computer-based interventions was variable, with use often decreasing over time.

Conclusion: Interventions delivered via telephone and computer have the potential to augment existing dementia care. High-quality trials are required to make clear recommendations about the types of interventions that are most effective. Those that provide caregivers with: access to practical strategies to manage care of the person with dementia and their own wellbeing, advice and support from peers and/or clinicians; and that target the dyad should be explored.
\end{abstract}

Keywords: Dementia, eHealth, Telephone, Caregiver, Technology, Internet

\section{Background}

Dementia can have complex health, practical and social consequences for the person living with dementia and their family. Most people with dementia (70\%) live in the community [1]. People with dementia may report a range of physical, psychosocial and practical concerns. If left unmet, these concerns may adversely impact quality of life $[2,3]$. Informal caregivers are often called on to

\footnotetext{
* Correspondence: amy.waller@newcastle.edu.au

${ }^{1}$ Health Behaviour Research Collaborative, School of Medicine and Public Health, University of Newcastle, Callaghan, NSW 2308, Australia

${ }^{2}$ Hunter Medical Research Institute, Newcastle, NSW 2305, Australia

Full list of author information is available at the end of the article
}

help manage activities of daily living, behavioural and psychological symptoms; and organise care and provide emotional support [4]. Caregiving has been linked to health and psychosocial concerns [5].

The need to improve care of people with dementia and to better support their caregivers across multiple domains has been emphasised [6]. These include the need for improvements in the quality of information available to this population; the implementation of care plans tailored to individual needs; and greater support for caregivers to ensure they are able to respond to the concerns of the person with dementia while managing their own health [6]. Limited awareness within the 
community about services available to provide support; insufficient provider time, skills or resources to deliver care $[7,8]$; and inconsistencies in monitoring and management of physical, psychosocial and practical concerns can result in fragmented dementia care [6].

Health resources are stretched to capacity, and there are a range of geographical, practical and system barriers to optimal dementia care [9]. The subsequent demands placed on caregivers of people with dementia means face-to-face support services can be burdensome or impractical. Hence, the delivery of services via alternative means, such as by computer or telephone, may allow individualised support of a broad cross-section of consumers in a timely way. More than half of people aged over 65 [10-12]; and up to $80 \%$ of caregivers of older adults are internet users [13]. These modes of delivery can facilitate the provision of credible information and resources that enable consumers to exercise control over their lives, and promote efficient communication between consumers and health care teams. Systematic reviews highlight the potential benefits of interventions delivered by professionals to caregivers of people with dementia [14]. Others describe benefits of interventions delivered via telephone or computer for other patient groups and their caregivers, including improvements to quality of life, perceived support, knowledge and satisfaction (e.g. [15-17]). The need for further research is emphasised, particularly given the rapidly changing technology field. Determining the effectiveness of interventions for specific caregiver groups is important, as there may be variation in complexity and severity of needs experienced by caregivers and the people they support. While there has been some synthesis of the evidence for computer and telephone interventions designed for caregivers of people with dementia $[18,19]$, none have examined the type, quality and impact of research.

To provide a comprehensive overview, several aspects of the available literature should be explored. The volume and type of research represents an indication of broad research effort. These indices can identify gaps that can be targeted by further research to guide practice and policy. Establishing the quality of the research [20] can reveal areas where increased capacity through further training or allocation of resources may be required. The aims of this review were to examine the extent to which computer and telephone delivered interventions for caregivers of people with dementia have been examined in the literature, including the: 1) volume and type of data-based publications; 2) methodological quality of intervention studies according to Effective Practice and Organisation of Care (EPOC) criteria; and 3) the effectiveness, acceptability and utilisation of interventions in studies that met minimum criteria for quality.

\section{Methods \\ Definition of interventions}

Included interventions were conceptualised as either: interventions incorporating components delivered via computer, tablet, website, e-mail, or mobile app; or interventions delivered via text messaging, telephone calls, or telehealth/videoconferencing modalities.

\section{Search strategy}

Medline, Embase, CINAHL and Cochrane Library of Critical Reviews electronic databases were searched from 1990 to Dec 2016 using subject headings and keywords (Additional file 1). The reference lists of existing systematic reviews and all eligible intervention studies were manually searched.

\section{Inclusion/exclusion criteria}

Studies were included if they: (i) examined interventions as defined above; (ii) included people providing unpaid/informal support to someone living with dementia (aged 18 years or over); (iii) examined one or more of the following outcome(s): health-related effects (e.g. impact of caring for someone living with dementia, quality of life, depression, satisfaction with care, self-efficacy), health care utilisation and/or costs (e.g. hospital admission, length of stay). Studies with a heterogeneous sample were included if they reported outcomes separately for caregivers. Studies were excluded if they: (i) were reviews, case studies, commentaries, conference abstracts, editorials or protocol papers; (ii) tested interventions that were not caregiveroriented (e.g. education of professionals).

\section{Data coding}

The abstract and title of retrieved articles were initially assessed against the eligibility criteria by one reviewer and rejected if the study did not meet inclusion criteria. The remaining full-text studies were assessed against the inclusion criteria by one author, and studies which met all criteria were retained. A random sample of $20 \%$ was coded independently by another author. Discrepancies between the two authors were resolved through discussion. Studies were categorised as either measurement, descriptive or intervention. Measurement studies reported on the development or psychometric properties of tools to assess utilisation and/or acceptability. Descriptive studies reported on perceived acceptability, access or utilisation of interventions. Intervention studies testing the effectiveness of interventions that had a primary aim of improving health outcomes, health care utilisation or costs for caregivers of people with dementia.

\section{Assessment of methodological quality}

Intervention studies were assessed to determine whether the experimental design was one of the four types 
allowed by the EPOC design criteria - randomized controlled trials, controlled trials, controlled before and after studies, or interrupted time series studies [21]. Stepped wedge designs were also included as they are a viable alternative to a parallel cluster randomised trial and accepted as a robust design. For those studies meeting minimum design criteria, methodological quality was then assessed using EPOC risk of bias criteria independently by two reviewers (AW and SD).

\section{Assessment of intervention effectiveness}

Study data was extracted for those studies that met EPOC criteria by authors (AW, SD, EM) and included: sample characteristics, intervention details, outcome measures and time points when data were collected, intervention effects on primary and secondary outcomes, study limitations and conclusions. Study data on feasibility and acceptability, including: retention of participants; access to the internet; engagement strategies; and utilisation of technologies was also reported.

\section{Analysis}

Poisson regression was used to model trends over time in the numbers of publications. Percent change by year is presented and $P$-values were calculated from the Wald Chi-square.

\section{Results}

\section{Search results}

A flow diagram of the search strategy is provided in Fig. 1. After duplicates were removed, 3828 publications were identified and assessed against the eligibility criteria. A total of 185 publications met eligibility criteria and were included.

\section{Number and type of studies published between Jan 1990} and Dec 2016

Half of the eligible studies were descriptive studies $(n=92 ; 50 \%)$ (see Fig. 2). Four measurement studies were identified, which tested the validity and reliability of instruments to assess the utilization or acceptability of interventions. The remaining 89 studies (48\%) reported on interventions to improve the health outcomes of caregivers. Poisson regression shows evidence of the number of publications increasing by $13 \%$ each year $(p<0.001)$.

\section{Methodological quality of intervention studies}

Of the 89 intervention studies identified, only 34 met initial EPOC design criteria (45\%). These included a cluster randomised controlled trial, 30 RCTs, and four non-randomised controlled trials (see Table 1). The 34 studies were rated across each of the nine EPOC risk of bias criteria. Only two studies were low risk on all of the nine criteria; with ten studies rated as low risk on at

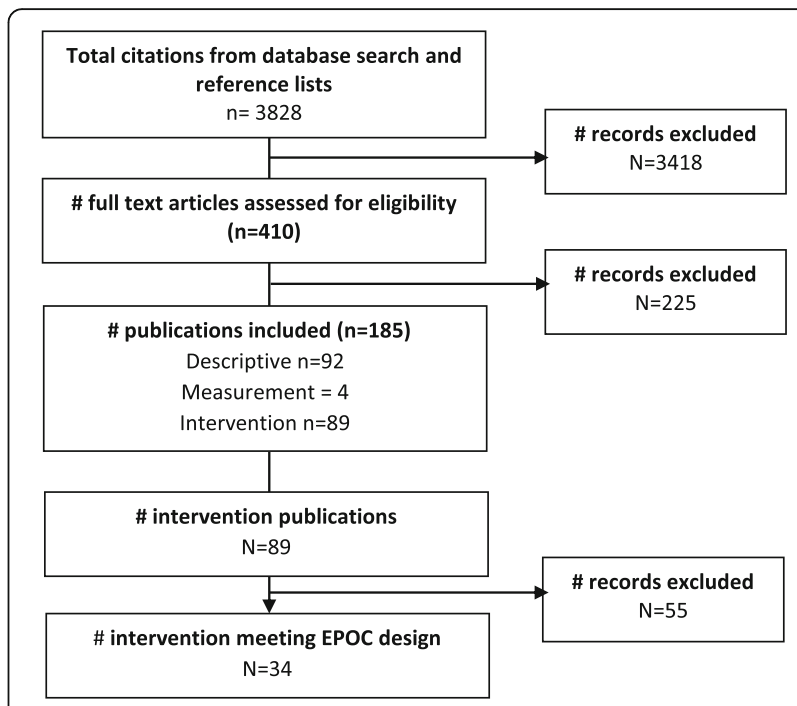

Fig. 1 Search strategy

least seven of the criteria. The most poorly met criteria included: not specifying method of generating allocation sequence or concealing allocation, and blinded outcomes assessment.

\section{Intervention study characteristics}

Table 2 presents the study characteristics of intervention studies that met EPOC design criteria $(n=34)$. Sample sizes ranged from 11 [22] to 299 [23] participants. The majority of the studies were conducted in the United States of America (USA) $(n=20)$, Europe $(n=8)$, China $(n=3)$, Canada $(\mathrm{n}=2)$ and the United Kingdom (UK) $(n=1)$. Ten interventions were delivered by computer only [22-31]; 15 via telephone [32-46]; and nine tested combined multiple modalities, such as computer-telephone systems [47-55]. Almost all adopted psychotherapeutic approaches: behavioural activation [36, 37, 54]; psycho-education alone or combined with cognitive behavioural therapy, skills training and/or peer support [23-32, 35, 38, 39, 50, 53, 55, 56]; peer support groups [33, 40,47, 48]; CBT [41-44]; or family therapy [49]. One study incorporated physical activity and psychotherapy [45]. Length of follow-up ranged from 1 month to 18 months. Attrition was moderate to high across studies (mean $=23 \%$, range 6\% [27]-61\% [41]); with differential dropout reported between the intervention group (40\%) compared to control (11\%) [28]. Some studies did not report rate or reasons for loss to follow-up $[22,24,26,33,34,38,48]$.

\section{Effectiveness, acceptability and utilization of technology interventions Computer-based interventions}

Ten interventions were delivered by computer only [22-31]. Benefits were reported in relation to 


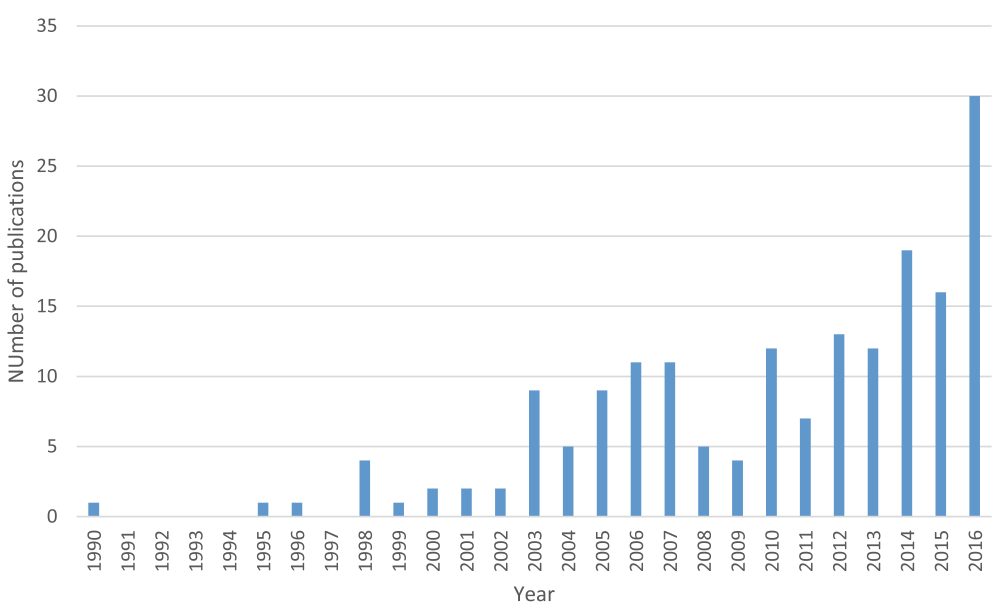

Fig. 2 Number of data-based publications by year January 1990-December 2016

caregiver depression and mental health outcomes in $3 / 8$ studies [23, 26, 28, 31]; and caregiver burden and/or stress (2/7 studies) (Additional file 2: Table of outcomes) [23, 26]. Other reported benefits included improved knowledge [22,30], quality of life [26] and unmet needs and more positive aspects of caring [23, 24, 29]. Web-based multimedia interventions providing written and audio-visual materials modelling positive caregiving strategies [23]; a program combined with coach monitoring [28]; and an online platform of educational material combined with peer and clinician contact [26] had modest success. The majority were judged as acceptable, easy to learn and userfriendly by caregivers. However, utilisation was variable. Two studies reported a dose-response relationship, with active users reporting greater benefits [23, 25]. Three studies incorporated online technical support to encourage engagement [22, 23, 27], while others used automated reminders [23, 28]; follow-up calls [27]; health professional contact via chat functions or forums [25]; and financial incentives [23, 29].

\section{Telephone interventions}

Twelve studies reported on the impact of telephone counselling using psychoeducation [32, 35, 37, 39, 46]; behavioural activation [36] or CBT [41-43]; alone and when supplemented with videos $[45,57]$ and respite care [38]. Mixed effects were reported in relation to caregiver depression and mental health outcomes (benefits in 6/12 studies) [32, 36-38, 43, 44]; and caregiver burden and/or stress (benefits in $4 / 11$ studies) [32, 38, 45]. Some reported improvements in goal attainment [42], physical symptoms/ADLs [45] and managing problems such as memory and behaviour $[32,46]$. No benefits were found for social support, self-efficacy and health and self-care outcomes. Rate of session participation was high in many studies [32, 35, 38, 42, 43, 45, 46], and participants reported the programs as helpful and convenient [32, 35, $38,39,41-44,46]$. Four studies reported that the intervention group received longer interventions than their attention-only control groups [42-44, 46].

Three studies examined the impact of telephone support groups. In one of these studies, support groups led to short-term cost savings for veteran care recipients living at home, but this was not maintained over 6 month period [34]. For the other two studies, no significant improvement in the impact of supporting a person with dementia, depression, social support or distress with relative's problems were identified $[33,40]$. The lack of effect did not differ by attendance [33]. Acceptability and utilisation data were not reported in two studies $[34,40]$.

\section{Multi-modal interventions}

Nine studies described multi-modal intervention programs. Four of these reported on aspects of the Resources to Enhance Alzheimer's Caregiver Health for TelephoneLinked Care (REACH) program. A computer-telephone psychoeducational program incorporated home and video-phone delivered family conferencing, online support groups and information resources. In one study, the program resulted in lower burden, and reduced depression for caregivers with elevated baseline depression [50]. However, another found no difference between integrated telephone and computer-network system intervention and control in relation to bother, depression or anxiety at 3 months [51]. In a third study, greater benefits were seen when the program was combined with family therapy [49]. Caregivers who received a psychosocial intervention modelled after REACH II, which included access to support groups via videophone technology, reported a decrease in burden, an increase in perceived social support and positive perceptions of the caregiving experience; but 


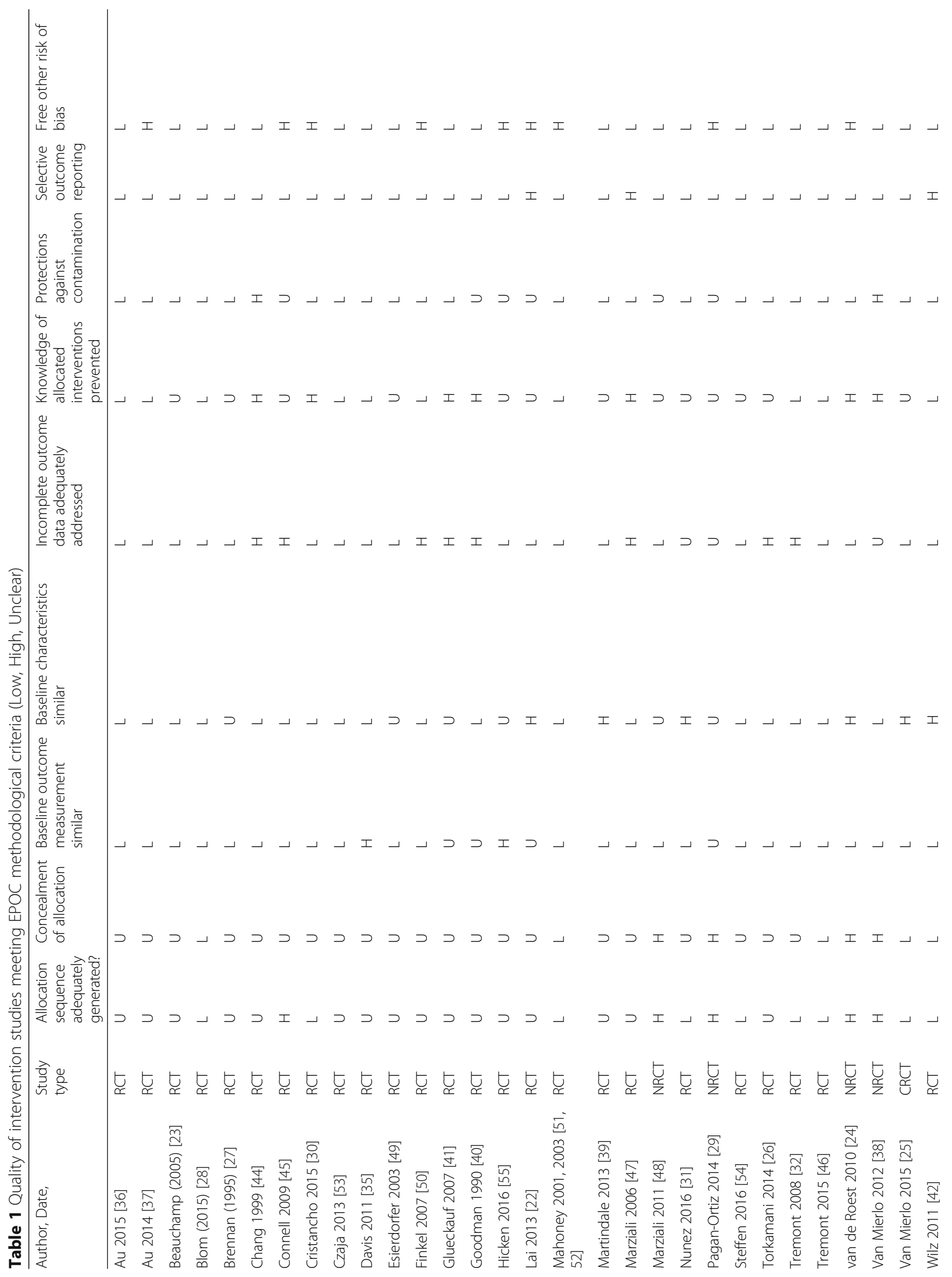




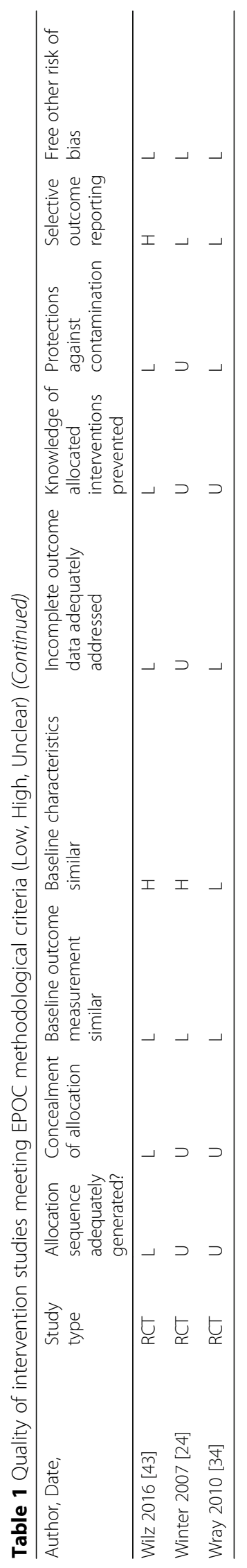




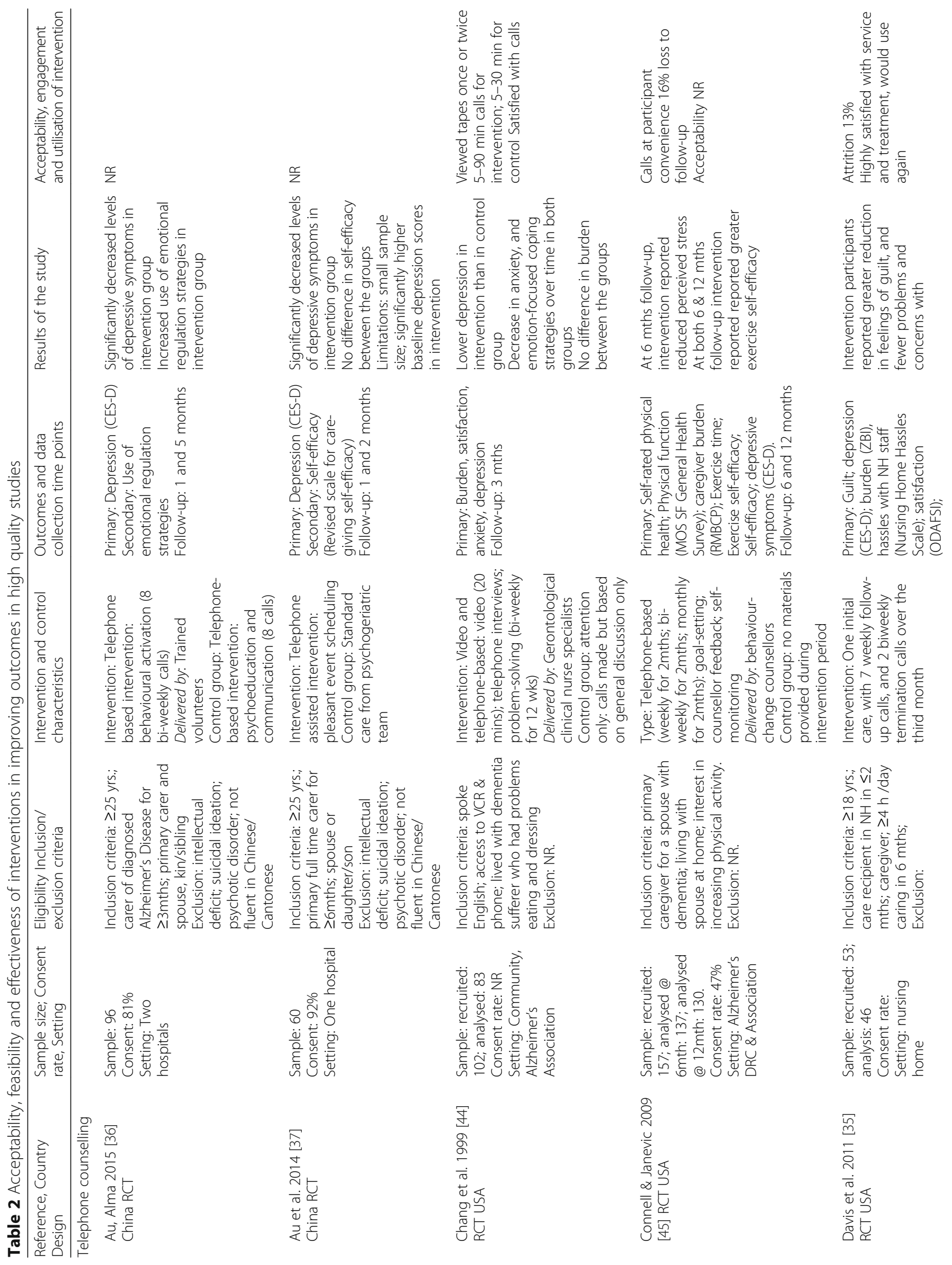




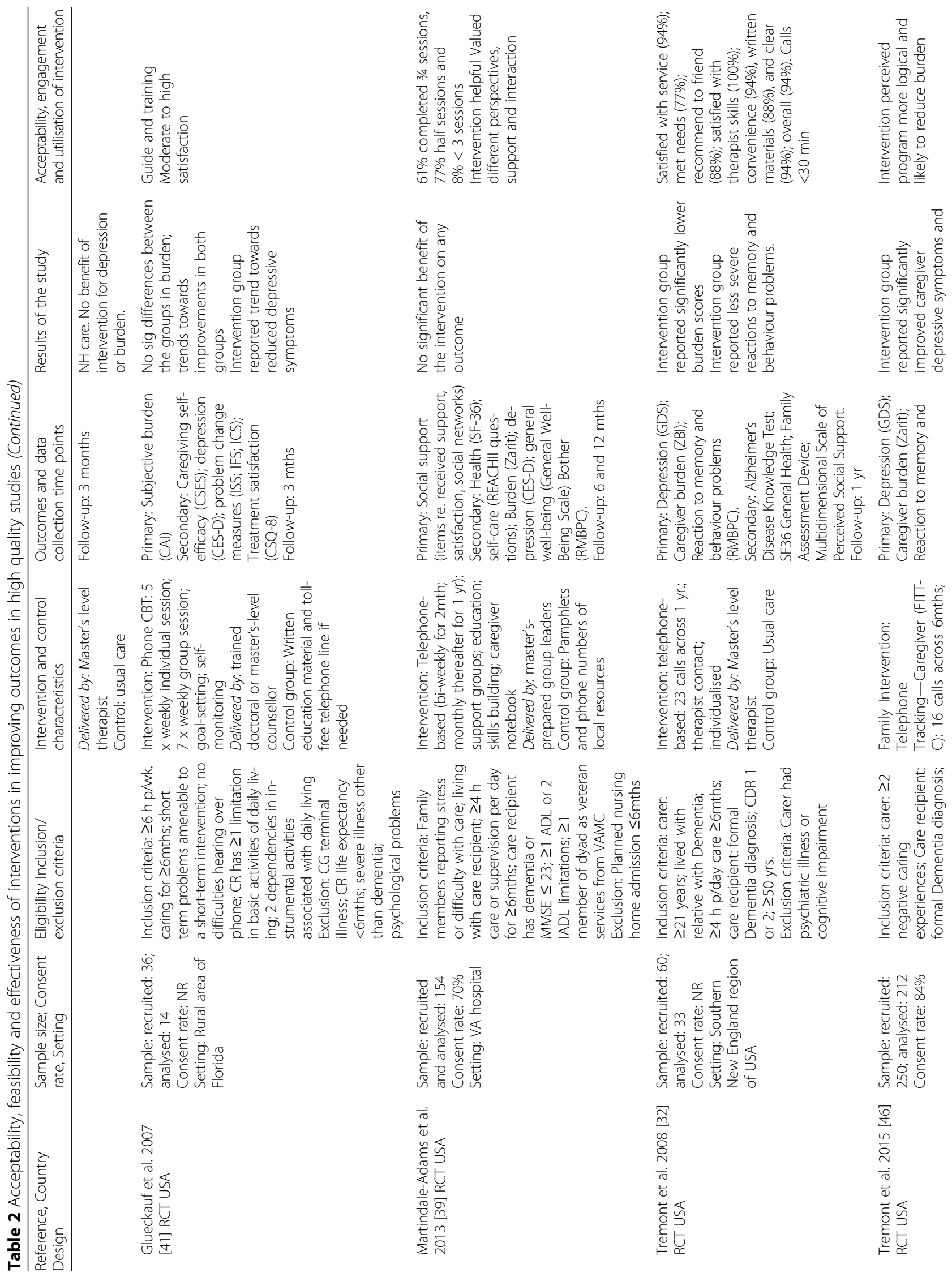




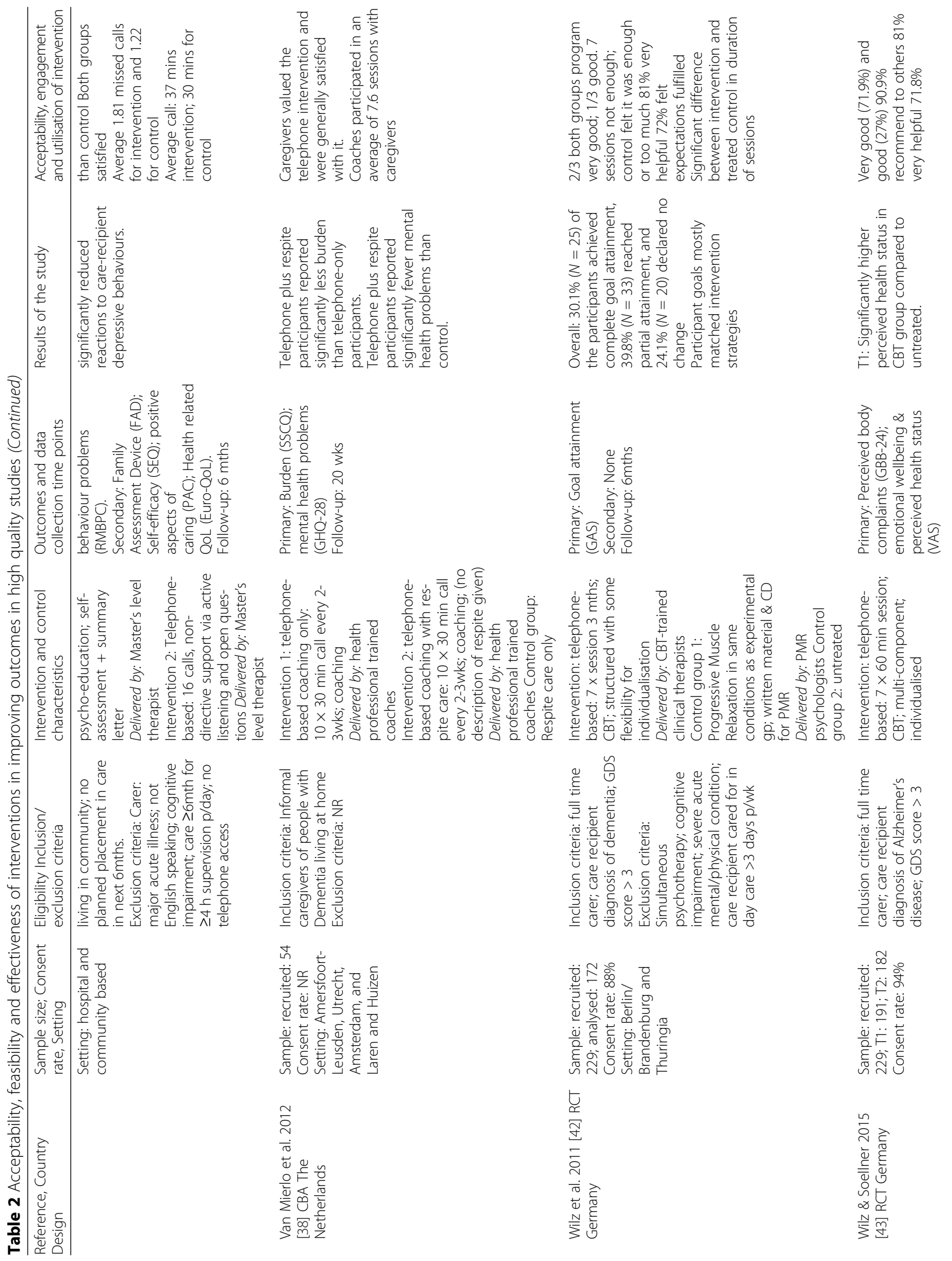




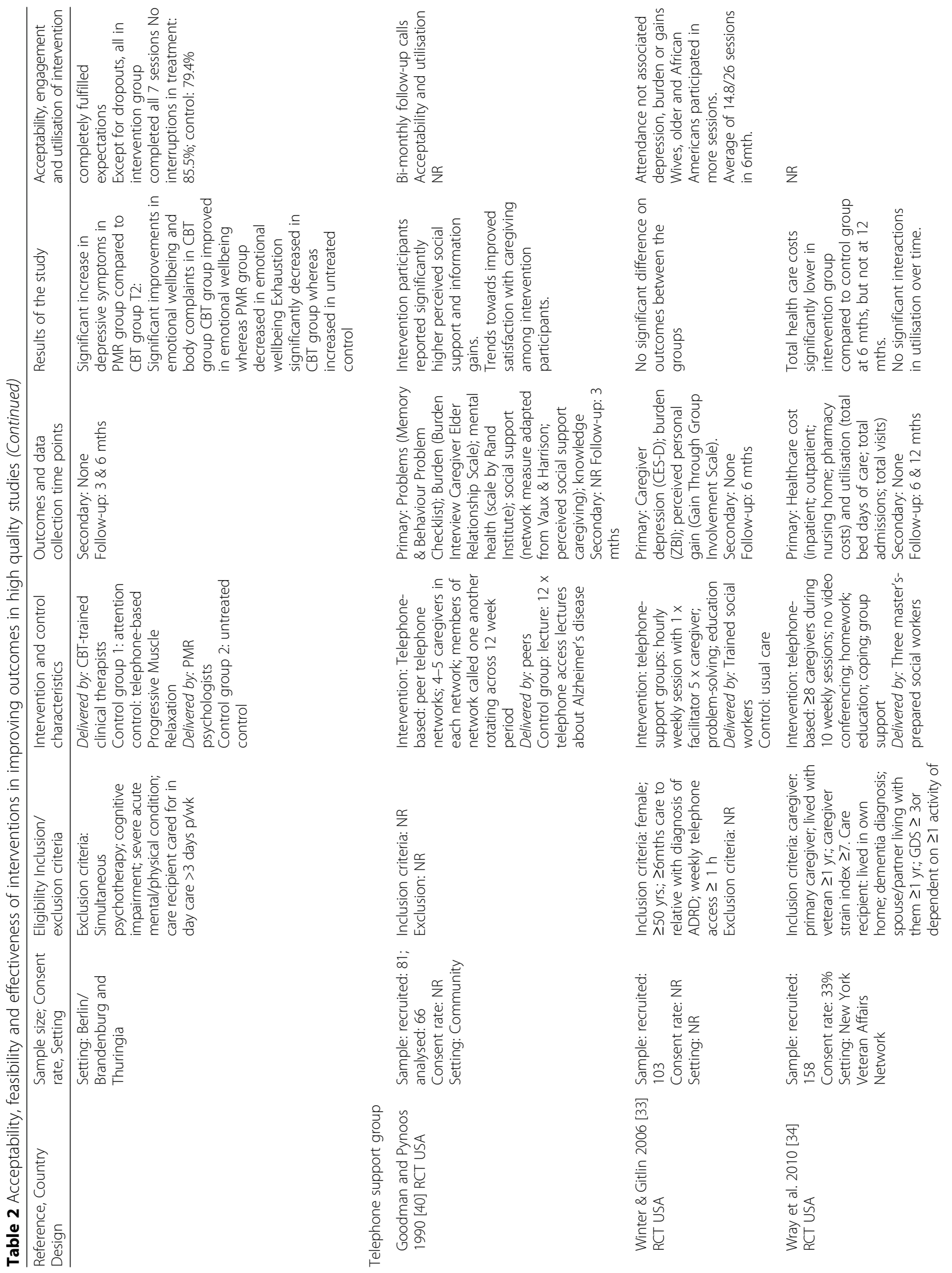




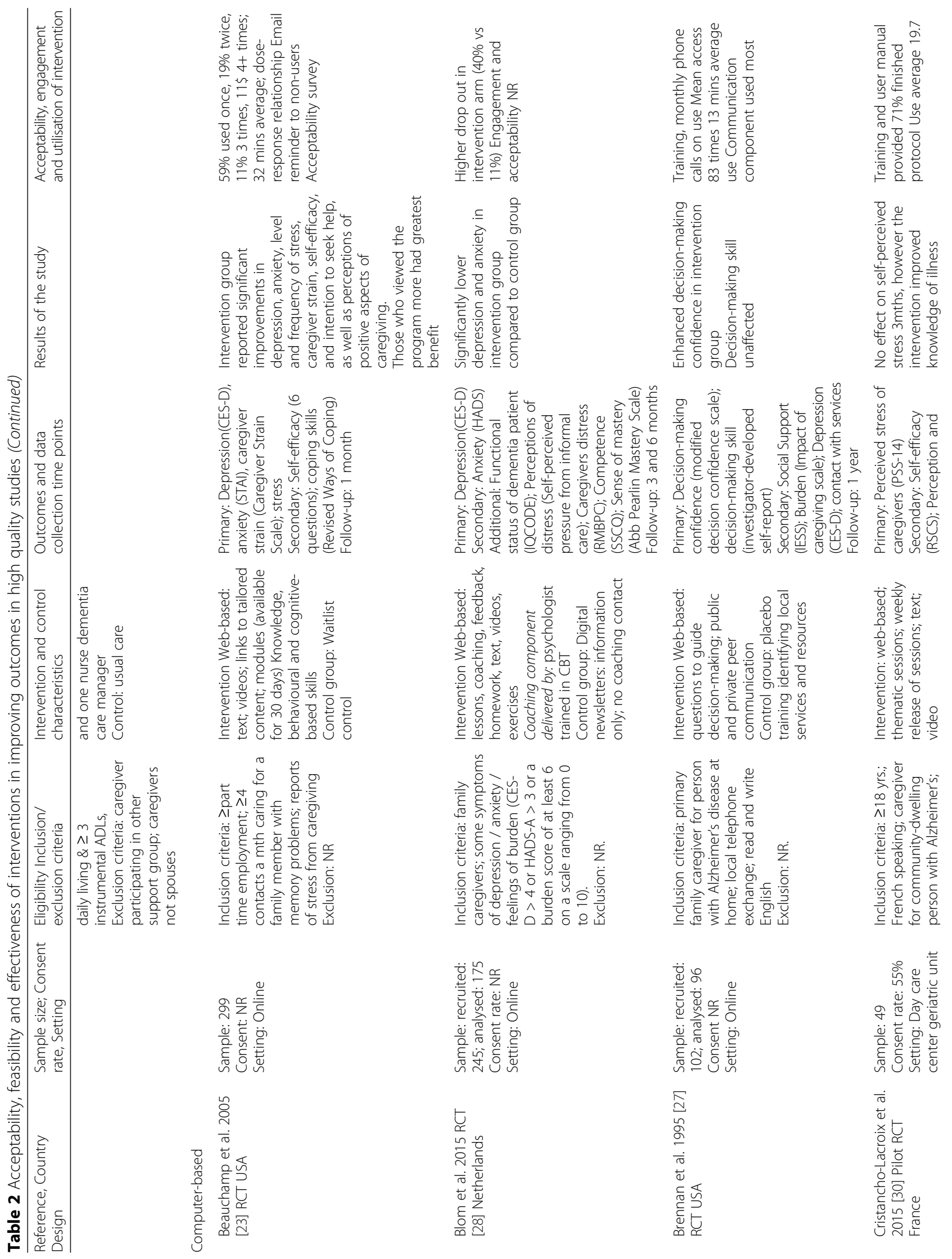




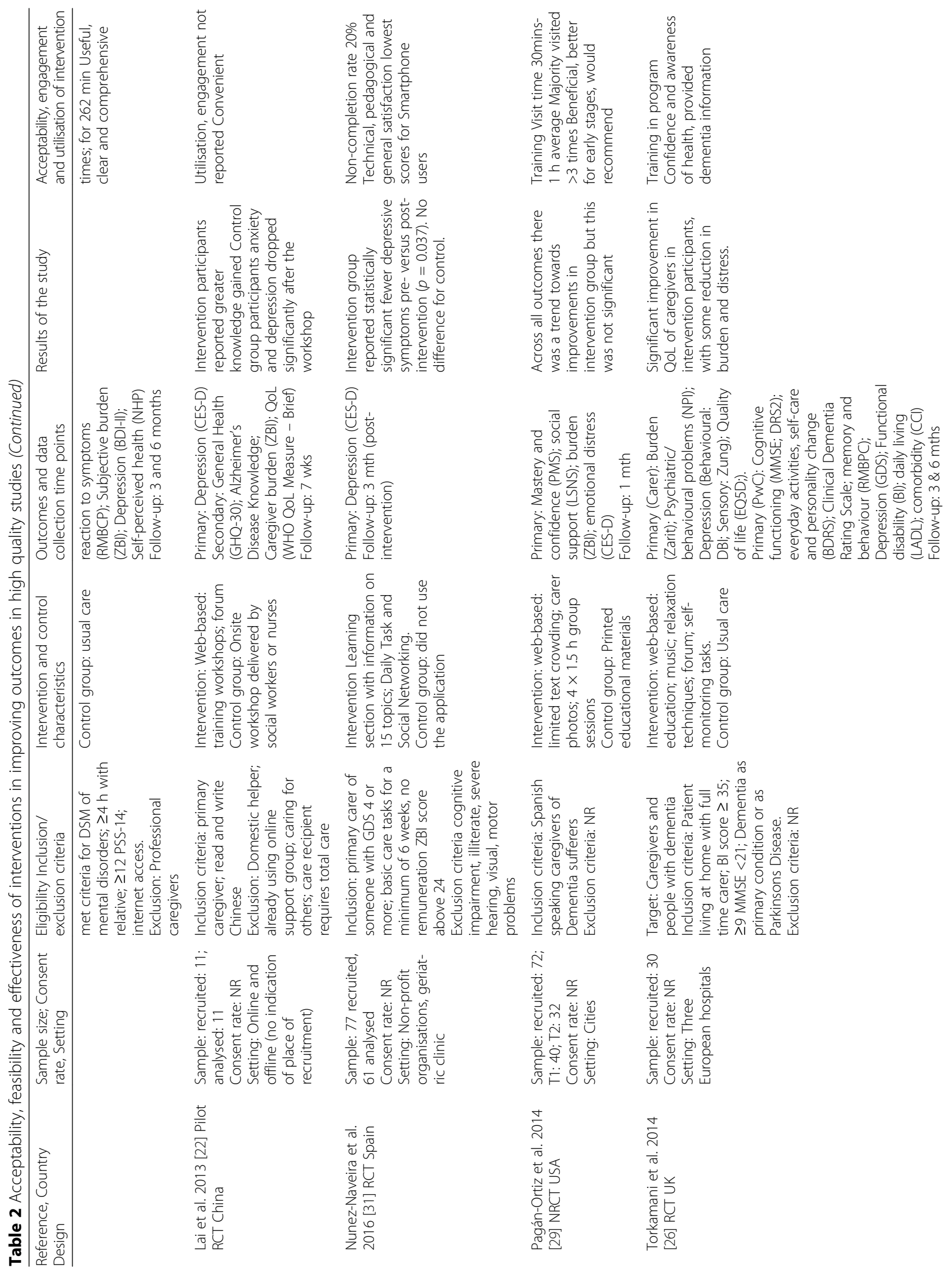




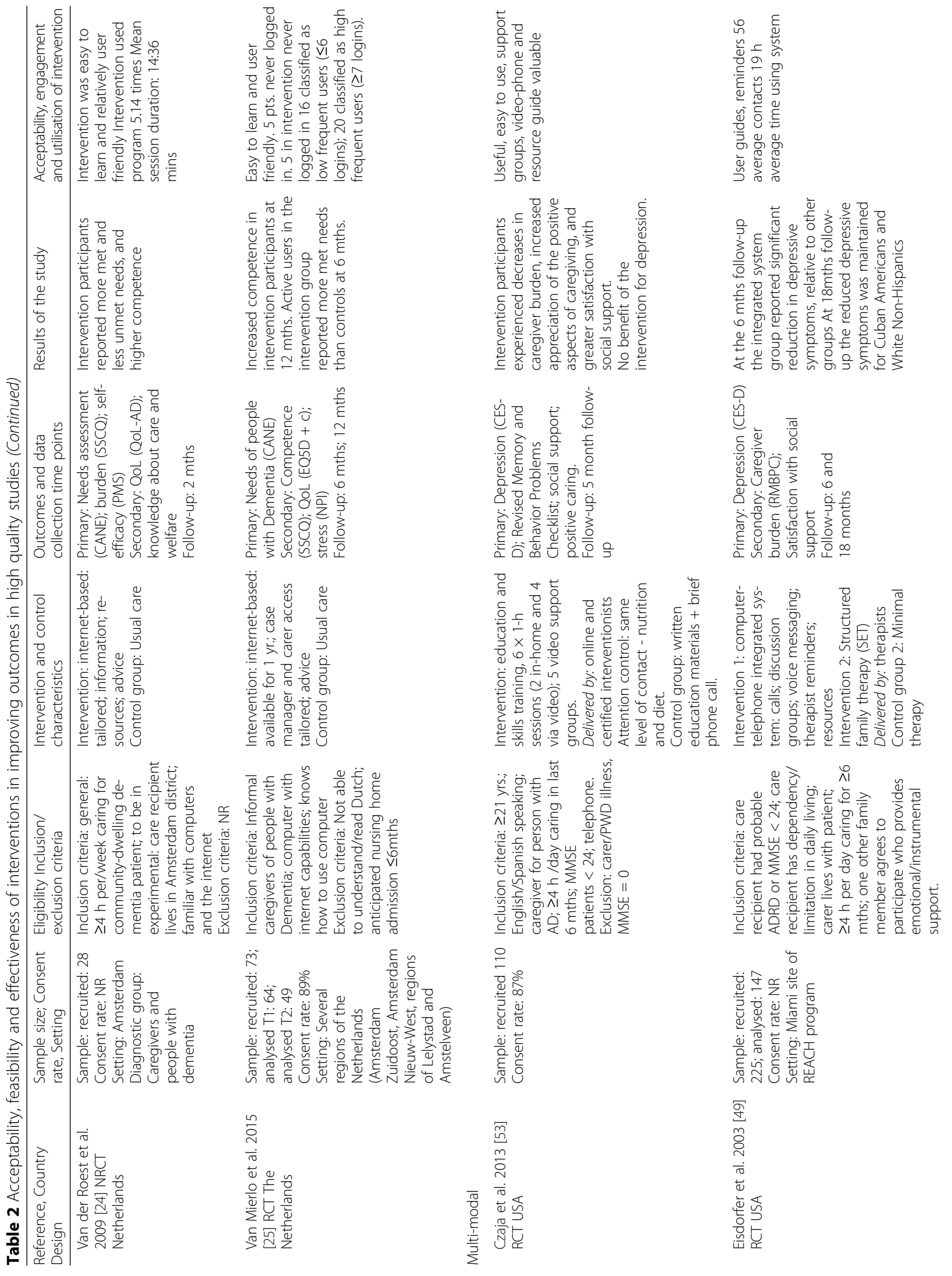




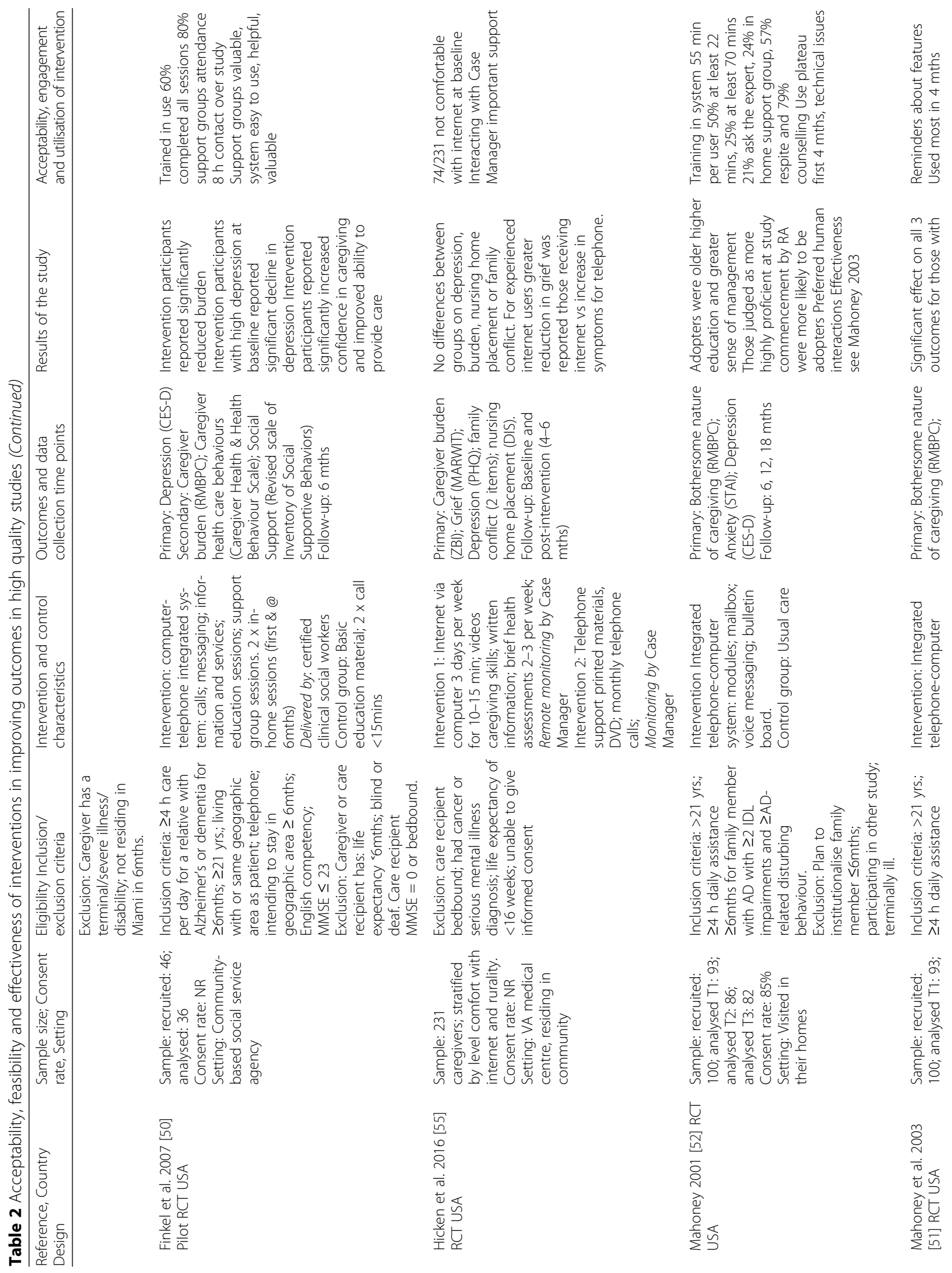




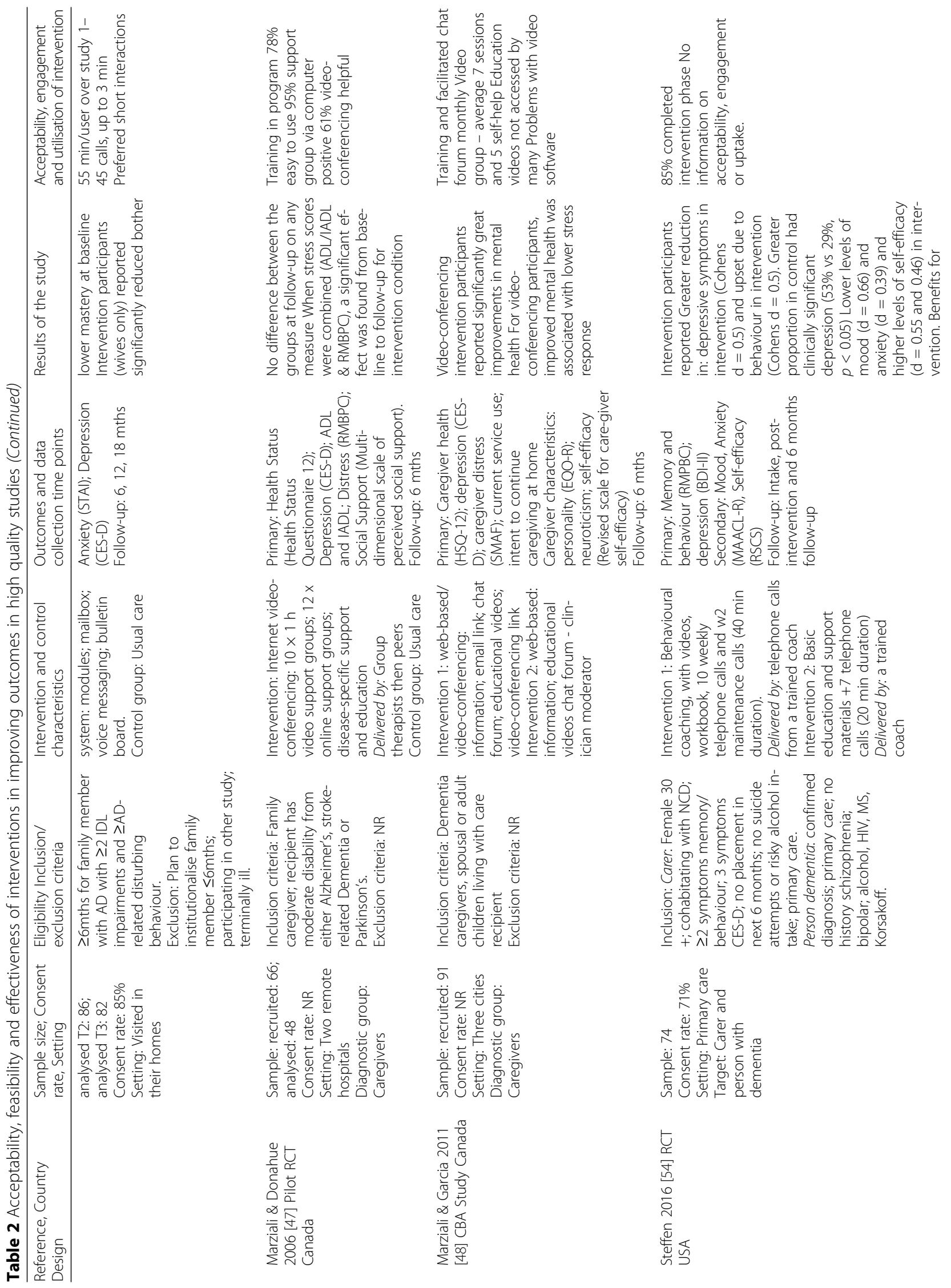




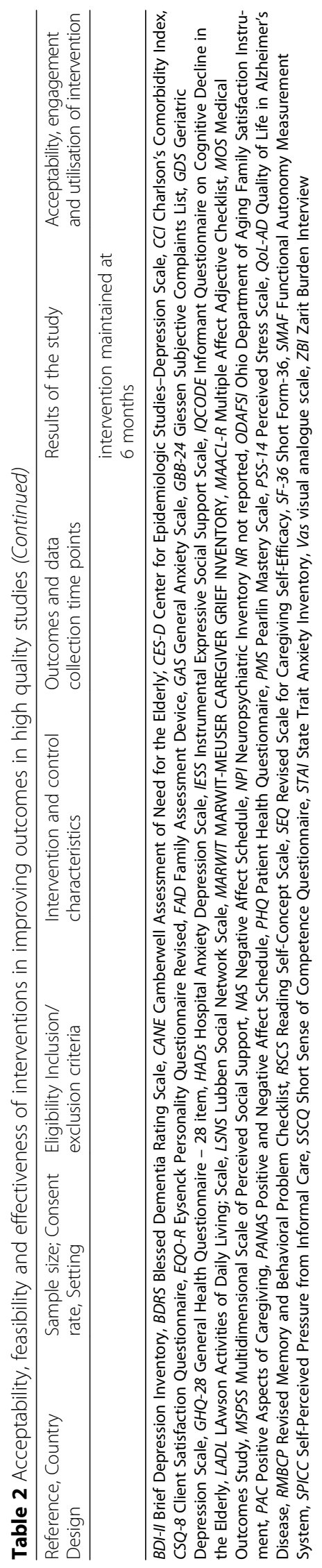


no benefit for depression [53]. Video-conferencing combined with online support led to greater improvements in mental health status compared to an internet chat group alone [48]. Providing the requisite technology or equipment $[48,50-53]$ and training were seen as an important for promoting uptake and ongoing engagement [48, 50-53]. However, some participants reported problems with using technology $[48,51,52]$. Behavioural coaching including videos, workbooks and telephone calls led to improvements in symptoms of depression, memory and behavioural problems, and caregiver self-efficacy [54]. No differences in outcomes were reported for a trial comparing internet versus telephone delivery of psycho-education, skills training and symptom assessments [55].

\section{Discussion}

The growing number of publications in this field reflects the increasing demand for strategies that can complement existing services and better support those providing informal care to people living with dementia. A high proportion of the total data based published studies were intervention studies (48\%). However, less than half of these identified interventions met initial EPOC design criteria. Most were uncontrolled before-and-after trials, which provide potentially promising feasibility data but require more rigorous testing. Only two studies were rated as methodologically sound on all the EPOC criteria. The evidence base may therefore be compromised by potential bias. Studies were also often characterised by poor response rates and attrition bias [30, 41, 45, 46], and short intervention / follow-up periods [24, 32, 35-37, $39,46]$. Loss to follow up due to death or significant health changes is expected conducting research with older people and people with dementia. However, adequately powered samples that take into account significant attrition rates should be a key consideration for future research.

Telephone counselling delivered over multiple sessions across many months was largely acceptable to caregivers. Mixed findings with regard to caregiver outcomes were reported. In the only telephone intervention study judged as low risk on all EPOC criteria, psychoeducation, skills training and health assessments improved depression and behavioural and memory problems [46]. Previous systematic reviews recognise the potential for telephone interventions in supporting people with dementia and their informal caregivers to maintain independence and wellbeing [19]. A lack of time and an inability to leave the person with dementia alone are major barriers to caregivers participating in face-to-face interventions. Telephone counselling may be a more feasible support option, but may still require more resources than are readily available. This may limit sustainability of such interventions.
In the only study of computer-based interventions to meet all EPOC criteria, psychoeducation with strategic access to clinicians via coaching support improved depression and anxiety [28]. Increasingly, innovations in mobile and tablet technology are being used to adapt care for caregivers of people with physical or cognitive impairment. Caregivers can access resources any time of the day, as often as they want. Multiple information formats can be adapted for health literacy or language. Content can also be readily updated or modified to incorporate other critical issues. However, success is reliant on the extent to which the intervention is actually being used. Differences between adopters and nonadopters were reported $[25,33,52]$; suggesting the need for greater consumer input during development. Attitudes towards technology may influence whether caregivers begin to use programs; while perceived competence may influence whether caregivers continue to use it [58].

\section{Implications for policy and practice and directions for future research}

Computer- and telephone-delivered interventions may assist in overcoming some of the deficits in current dementia care. Interventions that include psychoeducation via multiple formats, practical strategies and skills training to manage care, and peer and/or clinician contact hold promise. There are a number of potential advantages of these types of interventions. The reach of these interventions is significant and growing each year [59]. They can be delivered any time of the day, and from the comfort of the individual's home. This has particular advantages for caregivers of people with dementia with severe cognitive deficits and/or limited mobility, or those with poor access to specialised services or professionals [8, 60-62]. Features can be tailored for health literacy and cognitive deficits. For instance, information delivered via computer can be presented in written or audio-visual formats. Algorithms can tailor information according to user needs and preferences. Interventions can augment standard dementia care and improve efficiency of resource utilisation. Providers may supplement face-to-face consultations with interventions, or replace for those caregivers for whom face-to-face interventions are not feasible.

Despite these potential benefits, methodologically rigorous trials are needed to further identify the components of interventions effective in improving outcomes. Given evidence indicating dose effects, strategies to encourage uptake and continued utilisation of the intervention are crucial to ensure sufficiently exposure to achieve improvements. Proactive, personal and detailed invitations from clinicians and reminders have been shown to improve uptake of interventions and 
adherence [63-65]. It may also be useful to explore which of these strategies are most effective in maximising uptake and engagement. Interventions were rarely tested in other under-served populations, including ethnic minorities [55]. Few examined whether the intervention improved outcomes for the person living with dementia. It may be that providing education and skills training to carers may also result in beneficial effects for the person whom they support. Future research should further explore this possibility.

\section{Limitations of review}

Although the strategy was developed with the assistance of an academic medical librarian, indexing in this rapidly changing field may not have captured all relevant studies and we did not include non-published studies or grey literature. The authors only used the available reporting of research methods from the included publications to determine study quality ratings. Some quality criterion may have been met but received an 'unclear' rating when not adequately reported, potentially underestimating study quality. The review was limited to include only those studies that met EPOC criteria which restricted the study sample. While insights on the effectiveness of interventions may be obtained from studies using designs excluded by these criteria, these restrictions increase the likelihood of including studies with high quality evidence.

\section{Conclusions}

Interventions delivered via technology mediums, such as telephone and computer, have the potential to provide information and resources to improve outcomes of caregivers of people with dementia. However, more highquality intervention trials are required to make clear recommendations about which interventions are most effective in improving caregiver outcomes. Strategies are also needed to maximise utilisation of interventions. Interventions which provide practical strategies to upskill caregivers in managing the care of the person with dementia and their own wellbeing, access to peer and/or clinician support and advice and target the person with dementia and their caregiver as a dyad should be explored.

\section{Additional files}

Additional file 1: Search terms. The search terms used in the search strategy. (DOCX $14 \mathrm{~kb}$ )

Additional file 2: Summary table of outcomes. A summary of each of the primary and secondary outcomes assessed in each intervention. (DOCX $96 \mathrm{~kb}$ )

\section{Abbreviations}

ADL: Activities of daily living; CBT: Cognitive behaviour therapy; EPOC: Effective practice and organisation of care; NRCT: Non-Randomised controlled trial; RCT: Randomised controlled trial

\section{Acknowledgements}

The authors would like to acknowledge the assistance of Angela Smith from HNE Health Libraries who assisted with refining and conducting the literature search.

\section{Funding}

This research was supported by a National Health and Medical Research Council (NHMRC) Dementia Team Grant (APP1095078). AW is supported by an Australian Research Council Post-Doctoral Discovery Early Career Research Award.

Availability of data and materials

This paper is a systematic review. Articles selected for this review were referenced in bibliography. All data extracted from the selected studies were presented in the tables. There is no raw data to be made available.

\section{Authors' contributions}

AW and RSF conceived of and designed the review. SD, AW and EM undertook data extraction. All authors contributed to data analysis, drafting of the manuscript and have read and approved the final manuscript. All authors read and approved the final manuscript.

Ethics approval and consent to participate

Not applicable.

\section{Consent for publication}

Not applicable.

\section{Competing interests}

The author declares that they have no competing interests.

\section{Publisher's Note}

Springer Nature remains neutral with regard to jurisdictional claims in published maps and institutional affiliations.

\section{Author details}

${ }^{1}$ Health Behaviour Research Collaborative, School of Medicine and Public Health, University of Newcastle, Callaghan, NSW 2308, Australia. ${ }^{2}$ Hunter Medical Research Institute, Newcastle, NSW 2305, Australia. ${ }^{3}$ Priority Research Centre for Health Behaviour, University of Newcastle, Callaghan, NSW 2308, Australia.

Received: 3 July 2017 Accepted: 31 October 2017

Published online: 16 November 2017

\section{References}

1. Alzheimer's Australia: Caring for someone with dementia: the economic, social and health impacts of careing and evidence-based support for carers in.; 2015.

2. Arbaje Al, Kansagara DL, Salanitro AH, Englander HL, Kripalani S, Jencks SF, Lindquist LA. Regardless of age: incorporating principles from geriatric medicine to improve care transitions for patients with complex needs. Gen Intern Med. 2014;29(6):932-9.

3. McConaghy R, Caltabiano ML. Caring for a person with dementia: exploring relationships between perceived burden, depression, coping and wellbeing. Nursing \& Health Sciences. 2005;7(2):81-91.

4. Brodaty $H$, Donkin M. Family caregivers of people with dementia. Dialogues Clin Neurosci. 2009:11(2):217-28.

5. Alzheimer's Association. 2013 Alzheimer's disease facts and figures. Alzheimers Dement. 2013;9(2):208-45.

6. Laver K, Cumming RG, Dyer SM, Agar MR, Anstey KJ, Beattie E, Brodaty H, Broe T, Clemson L, Crotty M, et al. Clinical practice guidelines for dementia in Australia. Med J Aust. 2016;204(5):191-3.

7. Brodaty $\mathrm{H}$, Cumming A. Dementia services in Australia. International Journal of Geriatric Psychiatry. 2010;25(9):887-995.

8. Greenway-Crombie A, Snow P, Disler P, Davis S, Pond D. Influence of rurality on diagnosing dementia in Australian general practice. Australian journal of primary health. 2012;18(3):178-84.

9. McBride CM, Rimer BK. Using the telephone to improve health behavio and health service delivery. Patient Educ Couns. 1999;37(1):3-18. 
10. Perrin A, Duggan M. American's internet access 2000-2015. Pew Research Centre. June 2015.

11. Office of National Statistics. Internet Use in the UK. Published: 19 May 2017. Accessed: June 2017. https://www.gov.uk/government/statistics/internetusers-in-the-uk-2017.

12. Australian Bureau of Statistics. Household use of Information Technology, Australia 2014-15. Published: 18 Feb 2016. Accessed April 2017. http://www. abs.gov.au/ausstats/abs@.nsf/mf/8146.0.

13. Fox S, Brenner J. Family caregivers online. Washington, DC: Pew Internet \& American Life Project; 2012.

14. Huis In Het Veld JG, Verkaik R, Mistiaen P, van Meijel B, Francke AL. The effectiveness of interventions in supporting self-management of informal caregivers of people with dementia; a systematic meta review. BMC Geriatr. 2015;15:147.

15. Slev VN, Mistiaen P, Pasman HR, Verdonck-de Leeuw IM, van Uden-Kraan CF, Francke AL. Effects of eHealth for patients and informal caregivers confronted with cancer: a meta-review. Int J Med Inform. 2016:87:54-67.

16. Chi N-C, Demiris G. A systematic review of telehealth tools and interventions to support family caregivers. J Telemed Telecare. 2015;21(1):37-44.

17. Zheng $Y$, Head BA, Schapmire TJ. A systematic review of Telehealth in palliative care: caregiver outcomes. Telemedicine journal and e-health : the official journal of the American Telemedicine Association. 2016;22(4):288-94.

18. Boots $L$, de Vugt $M$, van Knippenberg R, Kempen G, Verhey F. A systematic review of internet-based supportive interventions for caregivers of patients with dementia. International journal of geriatric psychiatry. 2014;29(4):331-44.

19. Lins S, Hayder-Beichel D, Rucker G, Motschall E, Antes G, Meyer G, Langer G. Efficacy and experiences of telephone counselling for informal carers of people with dementia. Cochrane Database Syst Rev. 2014;9:CD009126.

20. Grimshaw JM, Eccles MP, Lavis JN, Hill SJ, Squires JE. Knowledge translation of research findings. Implementation science : IS. 2012;7:50.

21. Group CEPaOoCR. Suggested risk of bias for EPOC reviews. In. Oslo: Norwegian Knolwedge Centre for Health Services; 2015.

22. Lai CKY, Wong LF, Liu K-H, Lui W, Chan MF, Yap LSY. Online and onsite training for family caregivers of people with dementia: results from a pilot study. International Journal of Geriatric Psychiatry. 2013;28(1):107-8.

23. Beauchamp N, Irvine AB, Seeley J, Johnson B. Worksite-based internet multimedia program for family caregivers of persons with dementia. Gerontologist. 2005;45(6):793-801.

24. van der Roest HG, Meiland FJ, Jonker C, Droes RM. User evaluation of the DEMentia-specific digital interactive social chart (DEM-DISC). A pilot study among informal carers on its impact, user friendliness and, usefulness. Aging Ment Health. 2010;14(4):461-70.

25. Van Mierlo LD, Meiland FJ, Van de Ven PM, Van Hout HP, Droes RM. Evaluation of DEM-DISC, customized e-advice on health and social support services for informal carers and case managers of people with dementia; a cluster randomized trial. Int Psychogeriatr. 2015;27(8):1365-78.

26. Torkamani M, McDonald L, Saez Aguayo I, Kanios C, Katsanou MN, Madeley L, Limousin PD, Lees AJ, Haritou M, Jahanshahi M, et al. A randomized controlled pilot study to evaluate a technology platform for the assisted living of people with dementia and their carers. J Alzheimers Dis. 2014;41(2):515-23.

27. Brennan PF, Moore SM, Smyth KA. The effects of a special computer network on caregivers of persons with Alzheimer's disease. Nurs Res. 1995; 44(3):166-72.

28. Blom MM, Zarit SH, Groot Zwaaftink RB, Cuijpers P, Pot AM. Effectiveness of an internet intervention for family caregivers of people with dementia: results of a randomized controlled trial. PLoS One. 2015;10(2):e0116622. [Electronic Resource]

29. Pagan-Ortiz ME, Cortes DE, Rudloff N, Weitzman P, Levkoff S. Use of an online community to provide support to caregivers of people with dementia. J Gerontol Soc Work. 2014;57(6-7):694-709.

30. Cristancho-Lacroix V, Wrobel J, Cantegreil-Kallen I, Dub T, Rouquette A, Rigaud AS. A web-based psychoeducational program for informal caregivers of patients with Alzheimer's disease: a pilot randomized controlled trial. J Med Internet Res. 2015;17(5):e117.

31. Nunez-Naveira L, Alonso-Bua B, de Labra C, Gregersen R, Maibom K, Mojs E, Krawczyk-Wasielewska A, Millan-Calenti JC. UnderstAID, an ICT platform to help informal caregivers of people with dementia: a pilot randomized controlled study. Biomed Res Int. 2016;2016:5726465.

32. Tremont G, Davis JD, Bishop DS, Fortinsky RH. Telephone-delivered psychosocial intervention reduces burden in dementia caregivers. Dementia (14713012). 2008;7(4):503-20. 518p
33. Winter L, Gitlin LN. Evaluation of a telephone-based support group intervention for female caregivers of community-dwelling individuals with dementia. American Journal of Alzheimer's Disease and other Dementias. 2006:21(6):391-7.

34. Wray LO, Shulan MD, Toseland RW, Freeman KE, Vasquez BE, Gao J. The effect of telephone support groups on costs of care for veterans with dementia. Gerontologist. 2010;50(5):623-31.

35. Davis JD, Tremont G, Bishop DS, Fortinsky RH. A telephone-delivered psychosocial intervention improves dementia caregiver adjustment following nursing home placement. International Journal of Geriatric Psychiatry. 2011;26(4):380-7.

36. Au A. Developing volunteer-assisted behavioral activation teleprograms to meet the needs of Chinese dementia caregivers. Clinical Gerontologist: The Journal of Aging and Mental Health. 2015;38(3):190-202.

37. Au A, Wong MK, Leung LM, Leung $P$, Wong A. Telephone-assisted pleasantevent scheduling to enhance well-being of caregivers of people with dementia: a randomised controlled trial. Hong Kong Medical Journal. 2014; 20(3 Suppl 3):30-3.

38. van Mierlo LD, Meiland FJ, Droes RM. Dementelcoach: effect of telephone coaching on carers of community-dwelling people with dementia. Int Psychogeriatr. 2012;24(2):212-22.

39. Martindale-Adams J, Nichols LO, Burns R, Graney MJ, Zuber J. A trial of dementia caregiver telephone support. Can J Nurs Res. 2013;45(4):30-48.

40. Goodman CC, Pynoos J. A model telephone information and support program for caregivers of Alzheimer's patients. The Gerontologist. 1990;30:399-404.

41. Glueckauf RL, Sharma D, Davis WS, Byrd V, Stine C, Jeffers SB, Massey AJ, Wesley LM, McIntyre V, Martin C. Telephone-based cognitive-behavioral intervention for distressed rural dementia caregivers: initial findings. Clin Gerontol. 2007;31(1):21-41.

42. Wilz G, Schinkothe D, Soellner R. Goal attainment and treatment compliance in a cognitive-behavioral telephone intervention for family caregivers of persons with dementia. GeroPsych: The Journal of Gerontopsychology and Geriatric Psychiatry. 2011;24(3):115-25.

43. Wilz G, Soellner R. Evaluation of a short-term telephone-based cognitive behavioral intervention for dementia family caregivers. Clinical Gerontologist: The Journal of Aging and Mental Health. 2016:39(1):25-47.

44. Chang BL, Nitta S, Carter PA, Markham YK. Perceived helpfulness of telephone calls-providing support for caregivers of family members with dementia. J Gerontol Nurs. 2004;30(9):14-21.

45. Connell CM, Janevic MR. Effects of a telephone-based exercise intervention for dementia caregiving wives: a randomized controlled trial. J Appl Gerontol. 2009;28(2):171-94. 124p

46. Tremont G, Davis JD, Papandonatos GD, Ott BR, Fortinsky RH, Gozalo P, Yue MS, Bryant K, Grover C, Bishop DS. Psychosocial telephone intervention for dementia caregivers: a randomized, controlled trial. Alzheimer's and Dementia. 2015;11(5):541-8.

47. Marziali E, Donahue P. Caring for others: internet video-conferencing group intervention for family caregivers of older adults with neurodegenerative disease. Gerontologist. 2006;46(3):398-403.

48. Marziali E, Garcia L. Dementia caregivers' responses to 2 internet-based intervention programs. Am J Alzheimers Dis Other Demen. 2011;26(1):36-43.

49. Eisdorfer C, Czaja SJ, Loewenstein DA, Rubert MP, Arguelles S, Mitrani VB, Szapocznik J. The effect of a family therapy and technology-based intervention on caregiver depression. Gerontologist. 2003;43(4):521-31.

50. Finkel S, Czaja SJ, Schulz R, Martinovich Z, Harris C, Pezzuto D. E-care: a telecommunications technology intervention for family caregivers of dementia patients. Am J Geriatr Psychiatr. 2007;15(5):443-8.

51. Mahoney DF, Tarlow BJ, Jones RN. Effects of an automated telephone support system on caregiver burden and anxiety: findings from the REACH for TLC intervention study. Gerontologist. 2003;43(4):556-67.

52. Mahoney DM, Tarlow B, Jones RN, Tennstedt S, Kasten L. Factors affecting the use of a telephone-based intervention for caregivers of people with Alzheimer's disease. Journal of Telemedicine \& Telecare. 2001;7(3):139-48.

53. Czaja SJ, Loewenstein D, Schulz R, Nair SN, Perdomo D. A videophone psychosocial intervention for dementia caregivers. Am J Geriatr Psychiatr. 2013;21(11):1071-81.

54. Steffen AM, Gant JR. A telehealth behavioral coaching intervention for neurocognitive disorder family carers. International Journal of Geriatric Psychiatry. 2016;31(2):195-203.

55. Hicken BL, Daniel C, Luptak M, Grant M, Kilian S, Rupper RW. Supporting caregivers of rural veterans electronically (SCORE). J Rural Health. 2016;20:20. 
56. Gallagher-Thompson D, Wang PC, Liu W, Cheung V, Peng R, China D, Thompson LW. Effectiveness of a psychoeducational skill training DVD program to reduce stress in Chinese American dementia caregivers: results of a preliminary study. Aging Ment Health. 2010;14(3):263-73.

57. Chang BL. Cognitive-behavioral intervention for homebound caregivers of persons with dementia. Nurs Res. 1999:48(3):173-82. 110p

58. Chou WY, Liu B, Post S, Hesse B. Health-related internet use among cancer survivors: data from the health information National Trends Survey, 2003-2008. Journal of cancer survivorship : research and practice. 2011;5(3):263-70

59. ABS: Household use of information technology, Australia 2012-2013. In.; 2014.

60. National Aged Care Alliance. Assessment and the Aged Care Service. Position Paper. Released: Jan 2014. http://www.naca.asn.au/Publications/ Assessment\%20\%26\%20The\%20Aged\%20Care\%20Service\%20System\%20 Paper.pdf.

61. Coumarelos C, Macourt D, People J, McDonald HM, Wei Z, Iriana R, Ramsey S. Access to justice and legal needs. In., vol. 7. Law and Justice Foundation of NSW: Sydney; 2012

62. Cotten SR, Anderson WA, McCullough BM. Impact of internet use on loneliness and contact with others among older adults: cross-sectional analysis. J Med Internet Res. 2013;15(2):e39.

63. Kreuter MW, Chheda SG, Bull FC. How does physician advice influence patient behavior?: evidence for a priming effect. Arch Fam Med. 2000;9(5):426.

64. Vervloet M, Linn AJ, van Weert JCM, de Bakker DH, Bouvy ML, van Dijk L. The effectiveness of interventions using electronic reminders to improve adherence to chronic medication: a systematic review of the literature. J Am Med Inform Assoc. 2012;19(5):696-704.

65. Fry JP, Neff RA. Periodic prompts and reminders in health promotion and health behavior interventions: systematic review. J Med Internet Res. 2009; 11(2):e16.

\section{Submit your next manuscript to BioMed Central and we will help you at every step:}

- We accept pre-submission inquiries

- Our selector tool helps you to find the most relevant journal

- We provide round the clock customer support

- Convenient online submission

- Thorough peer review

- Inclusion in PubMed and all major indexing services

- Maximum visibility for your research

Submit your manuscript at www.biomedcentral.com/submit 